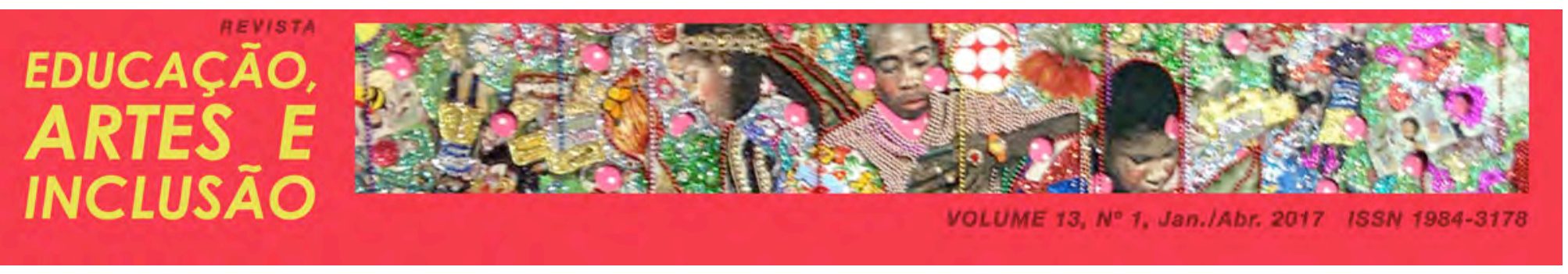

\title{
REMEXENDO O ESQUELETO: UMA PROPOSTA DE ENSINO DO SISTEMA ÓSSEO PARA SURDOS E OUVINTES
}

\section{MOVING THE SKELETAL: A TEACHING PROPOSAL OF THE BONE SYSTEM FOR DEAF AND HEARING}

DOI: http://dx.doi.org/10.5965/1984317813012017077

Josué Buracof Shimabuko Junior, Edna Lopes Hardoim - UFMT

\begin{abstract}
RESUMO
Historicamente, a educação de surdos esteve voltada para questões linguísticas, em específico, para a discussão do ensino da Língua Portuguesa, oral e/ou escrito, e do uso da língua de sinais. Pouco se tem falado em relação à aprendizagem de outras áreas do ensino, como as Ciências. Pesquisar e compreender metodologias que facilitem o ensino para esses alunos torna-se muito importante, visto que passamos por um período escolar onde o processo inclusivo inicia-se, e a atenção deve ser redobrada. A interação entre os diferentes no intuito de que percebam os outros e ocorra um auxílio mútuo, trazendo o olhar para a educação não apenas conteudista, mas visando o desenvolvimento humano, de compartilhamento de saberes/experiências. Objetivou-se despertar um olhar diferenciado nos professores quanto ao ensino para esses alunos, na tentativa de desmistificar a incapacidade de surdos na aprendizagem diferenciada que envolva elementos para os quais achamos necessária a audição, obtendo como resultado uma proposta de aula diferenciada para o ensino do Sistema Ósseo tendo a dança como elemento introdutório e motivador.
\end{abstract}

PALAVRAS-CHAVE: EJA; Ciências; Inclusão.

\begin{abstract}
Historically, the deaf education was focused on linguistic questions, in particularly; in discuss the education of the Portuguese language, oral and/or written, and the use of sign language. In the history, shortly was discussed in relation to learning of other areas of education, such as science. Researching and comprehending the methodologies to facilitate the education for deaf students becomes very important, since we are going through a period where the school inclusive process begins, and attention should be reinforced considering that all the students has education rights an equal form. The interaction between the different in order to realize the existence of the other, and happen a mutual aid, not only in a formal education, but also in aiming the human development of sharing knowledge/experiences. This study also aimed awaken a different teachers' view to teach these students, in attempt to demystify the disability of the deaf in differentiated learning that involves elements which is thought the audition is essential, obtain as a result a proposal to one differentiated lesson to the teach of Skeletal System having the dance as introductory and motivator subject.
\end{abstract}

KEYWORDS: EJA; Science; Inclusion. 


\section{INTRODUÇÃO}

A escola regular inclusiva é para todos e se constitui em espaço de múltiplas identidades, que traz vantagens para o desenvolvimento das relações humanas no âmbito escolar, dada a possibilidade real de interação entre as Pessoas Com Deficiência (PCD) e aqueles não deficientes. Se considerarmos que também é a partir das relações que as pessoas conseguem construir conceitos, o diálogo entre os diferentes revela-se essencial ao desenvolvimento cognitivo. A efetivação de uma educação de forma diferenciada permite perceber a existência das diferenças, respeitando-as e convivendo com estas de forma natural e não excludente. Entretanto, alguns requisitos precisam ser revistos para que possamos dar continuidade a essas mudanças de forma que a qualidade de ensino contemple a todos os alunos.

Especificamente para os alunos surdos, o foco deste trabalho, é necessário levar em consideração todo um desenvolvimento cognitivo que ocorre de forma distinta, já que os mesmos percebem o mundo por meio da visão, não possuindo recursos auditivos como referência, o que torna esse grupo de pessoas perceptíveis de um mundo diferente dos ouvintes, com algumas peculiaridades, a começar por sua língua natural que tende a ser visoespacial e não oral-auditiva. Strobel (2013) nos aponta que é preciso considerar toda essa especificidade em relação a língua, cultura e, principalmente, atentar para sua forma de aprendizagem, afinal, o surdo é mais uma entre as tantas outras identidades presentes no espaço escolar inclusivo.

Outra autora com posicionamento semelhante é Lopes (2011), que considera em sua obra um outro olhar para o sujeito surdo, com o qual nos identificamos enquanto pesquisadores. Ela entende a surdez como um traço cultural não negando seu caráter natural, mas sim, pensando na surdez como elemento do circuito cultural que não pode ser esquecido ou relegado a comparações entre ouvintes e surdos. Essa diferença cultural, para a autora, coloca-se dentro da necessidade de estabelecer comparações ente sujeitos pertencente a grupos culturais distintos.

Historicamente, a educação de surdos esteve voltada para questões linguísticas, em específico, para a discussão a aprendizagem do português oral e/ou escrito, e do uso da língua de sinais (QUADROS, 2004). Muito pouco se falou em relação à aprendizagem de outras 
áreas do ensino e como estas ocorriam. Desta forma, faz-se necessário ressaltar a importância de pesquisas em outras áreas do conhecimento, referentes à aprendizagem do aluno surdo, como na área de Ciências da Natureza, que motivam o aluno a buscar respostas a questões e fenômenos, do cotidiano ou não, e podem deixar o sujeito curioso, interessado e, por vezes, aguçam o desejo de explorar aquilo que parece diferente. Por quê? Essa é uma pergunta frequente, se não diária, na vivência do ser humano.

Poucos autores têm se dedicado ao ensino de ciências para surdos no Brasil, entre eles estão: Machado (2003) Lemos Neto et al. (2007); Pereira Benite \& Benite (2011), se tornando, assim, um dos nossos desafios enquanto educadores, a busca de métodos e instrumentos pedagógicos que nos permitam trabalhar com os diversos, posto que possuem cultura e ritmo próprio, mas que cotidianamente são submetidos a fenômenos e processos iguais ou semelhantes ao dos ouvintes.

Quando falamos de ensino de ciências, e a Biologia pertence a esta grande área, tornase muito importante pesquisar e compreender metodologias que facilitem a aprendizagem de temáticas por alunos com deficiência, uma vez que passamos por um período na história da educação em que o processo de inclusão inicia-se. Entendemos inclusão como Sassaki define ser:

O processo pelo qual a sociedade se adapta para poder incluir, em seus sistemas sociais gerais, pessoas com necessidades especiais e, simultaneamente estas se preparam para assumir seus papéis na sociedade. A inclusão social constitui, então, um processo bilateral no qual as pessoas, ainda excluídas, e a sociedade buscam, em parceria, equacionar problemas, decidir sobre soluções e efetivar a equiparação de oportunidades para todos (SASSAKI, 1997, p. 41).

Quando pesquisamos sobre o tema, algumas das contribuições de Levi Semiovitch Vigotski são fundamentais, visto que elas nos apontam a importância da interação dos envolvidos para a aprendizagem e nos trazem valores que devem ser considerados, como a interação entre professor e aluno, aluno e colegas. Tais interações precisam ser motivadas pelo docente, possibilitando por meio de metodologias de ensino que proporcionarão um maior contato com os colegas, gerando a aprendizagem. Não podemos esquecer que ainda nestas relações temos a presença de um mediador da comunicação entre o aluno surdo e os 


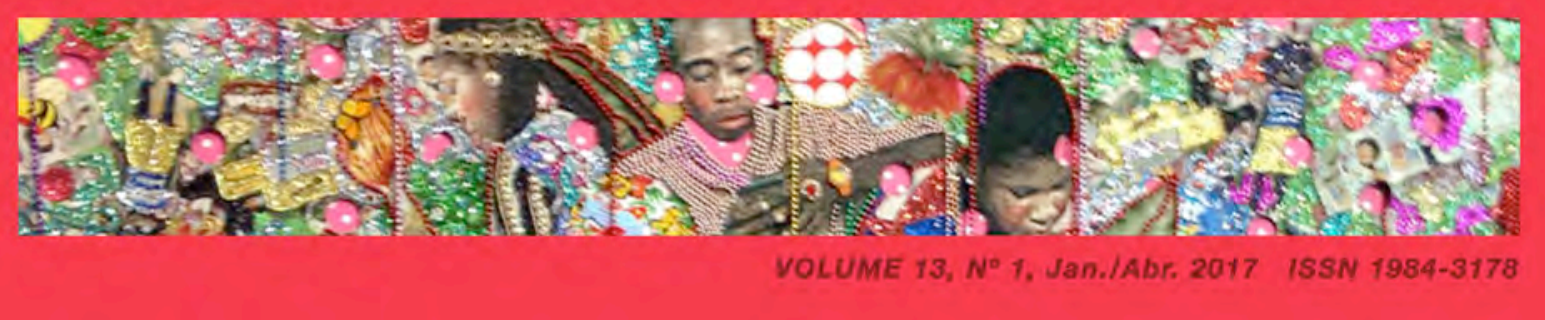

demais ouvintes - o Intérprete de LIBRAS (ILS), e sua relação neste processo de ensinoaprendizagem precisa ser levada em consideração.

Vigotski (1999) defende o sócio interacionismo como sendo uma das bases para a aprendizagem e desenvolvimento da linguagem. A interação entre os diferentes, no intuito de que uns percebam os outros e ocorra auxílio mútuo, traz o olhar para a educação não apenas como um local preocupado com a formação conteudista, mas, sobretudo, com uma visão de desenvolvimento humano, compartilhamento e produção de saberes.

Uma escola inclusiva, tendo como aporte, as concepções de Vigotski (2008) "Privilegia as mediações culturais, que caracterizam sua visão do humano enquanto ser social, atribuindo o exercício da humanidade à possibilidade de o indivíduo estabelecer trocas culturais por meio da linguagem". Portanto, a falta de compreensão de uma linguagem, independente de qual seja, acarreta, em especial, na criança atraso em seu desenvolvimento cognitivo e na aprendizagem, comprometendo, também sua capacidade de interação com outros sujeitos no seu meio.

Para Hardoim et al (2013, p. 2), os talentos e potenciais das PCD não foram considerados ao longo da história, pois sempre foi mais fácil prestar atenção à aparência e as limitações do que às suas capacidades. Para essas autoras, ainda vivemos numa sociedade que começa a dar pequenos passos no sentido da inclusão dos diferentes e, principalmente, na proteção dos direitos humanos, considerando o humano como um ser portador de potencialidades na promoção do bem comum.

No intuito de entender esse processo, propomos a dança como um instrumento didático, pensando na possibilidade da vivência, em que os alunos consigam inter-relacionar a dança com a aprendizagem do sistema ósseo, possibilitando uma aprendizagem significativa para todos. Campos e Nigro (2009), assim como outros autores, acreditam que as atividades práticas possibilitam desenvolver a autonomia dos alunos, promover a aprendizagem significativa, transformar a visão da ciência como uma interpretação do mundo e não de respostas prontas, possibilitando relacionar ciência e seu cotidiano, sem ultrapassar seus limites do desenvolvimento cognitivo. Ausubel nos diz que: 
A essência do processo de aprendizagem significativa é que ideias simbolicamente expressas sejam relacionadas de maneira substantiva (nãoliteral) e não arbitrária ao que o aprendiz já sabe, ou seja, há algum aspecto de sua estrutura cognitiva especificamente relevante para a aprendizagem destas ideias (AUSUBEL, 1978, p. 41)

O autor acredita que esta aprendizagem ocorre quando uma nova informação se relaciona com um aspecto especificamente relevante da estrutura de conhecimento do indivíduo, ocorrendo a interação entre a nova informação e o conhecimento específico já assimilado, o que ele denomina de subsunçor ${ }^{1}$.

Outras condições são necessárias para que tal aprendizagem ocorra, como um material potencialmente significativo e a disposição do aluno para relacionar de maneira substantiva o novo material. Independentemente do quão o material seja potencialmente significativo, se não for interessante para o aluno, se o mesmo não estiver disposto a aprendê-lo, tal aprendizagem será de forma mecânica, arbitrária e não terá significado para o aprendiz.

Nossa sociedade compartilha um ponto de vista clínico em relação às pessoas com surdez. Os que desconhecem a cultura surda, bem como a LIBRAS, em sua maioria, não cogitam a possibilidade de pessoas surdas dançarem por relacionar a audição como sentido fundamental para a execução dos movimentos. Entretanto, como nos coloca Skliar (2013), se considerarmos outra possibilidade de "ouvir", o escutar no sentido metafórico, a escuta, que solicita uma atitude de disponibilidade de todos os sentidos, ainda que "o ouvir" não se materialize como sentido fisiológico. Podemos dizer que as pessoas surdas escutam sem ouvir. Sendo assim, são aptas a desenvolver práticas culturais que envolvam tal atividade física.

A pesquisadora Strobel (2013) relata em seu livro que mesmo não sendo parte significativa para os surdos, ainda sim existem surdos que gostam de realizar a atividade cultural. Em uma passagem de sua obra relata:

${ }^{1} \mathrm{O}$ termo correto é "subsumer", palavra inglesa que não possui tradução fiel, equivalente a inseridor, facilitador ou subordinador (MOREIRA, 1999). 
Nos bailes e festas promovidos pelas associações de surdos, geralmente, no salão há poucos sujeitos surdos dançando.... Aqueles que dançam no salão... são sujeitos surdos que sentem a vibração da música e gostam de dançar... dançam livres, a sua maneira, afinal, nesses bailes e festas de cultura surda não há regras de ritmo musical correto e muitas vezes acontece que quando acaba a música, eles continuam dançando (STROBEL, 2013 p. 78).

Pensando dessa forma, quando nos propomos a estudar métodos ou estratégias pedagógicas que envolvam elementos culturais como a dança ou a música, geralmente, os alunos surdos são deixados de lado por pautarem que a audição está diretamente ligada a tais atividades, desconstruindo todo um processo inclusivo na escola, que barra seus alunos por possuírem "limitações físicas". Então, perguntamos: será mesmo que surdos não são capazes de dançar, desenvolver rítmica, lateralidade, consciência corporal por meio da dança pelo fato de não escutarem a música da forma como os ouvintes a escutam? Em geral, tal indagação nos leva a uma reflexão de que não podemos utilizar essas dinâmicas em salas com crianças surdas para não as tornar excluídas do processo educacional.

Ao pensar nestas problemáticas nos arriscamos a propor uma metodologia diferenciada para auxílio do professor de Biologia tendo como aporte teórico a conceituação de inclusão proposta por Sassaki (1997), o sócio interacionismo (VIGOTSKI, 2008) e a aprendizagem significativa (AUSUBEL, 1978), tentando mostrar um novo olhar sobre os surdos inclusos, a começar por desmistificar alguns pré-conceitos sobre estes.

Essa pesquisa objetivou construir uma proposta de aula diferenciada (AD) para o ensino do Sistema Ósseo, tendo a dança como elemento introdutório e motivador que possibilite uma $\mathrm{AD}$ e significativa para os envolvidos, promovendo a interação entre os alunos da sala - surdos e ouvintes - da escola inclusiva, possibilitando aprendizagem significativa do conteúdo do Sistema Ósseo por meio de experimentação.

\section{PERCURSO METODOLÓGICO}

Este roteiro de aula é fruto de uma pesquisa de mestrado no Programa de PósGraduação em Ensino de Ciências Naturais - da Universidade Federal de Mato GrossoPPGECN/UFMT, no ano de 2014. O estudo foi desenvolvido em seis etapas sendo: oficina de 


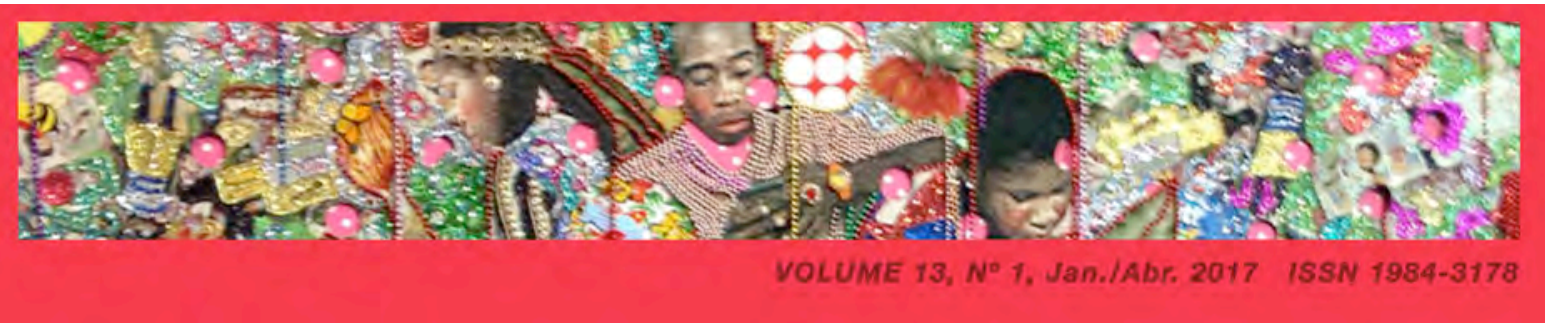

dança em uma escola especial de ensino para alunos surdos, a fim de compreender como eles percebem a música e a dança; observações das aulas de biologia na escola inclusiva, onde o roteiro de $\mathrm{AD}$ foi aplicado; entrevista com os envolvidos da escola inclusiva; produção da $\mathrm{AD}$; aplicação da $\mathrm{AD}$; e, por fim, as considerações sobre a aplicação. Contudo, neste trabalho, discorremos de forma resumida e com ênfase na construção da aula.

Não pensamos na dança como atividade que deveria ser executada com perfeição, observando os mínimos detalhes como a execução dos passos corretamente, dentro do ritmo visto, que estes não faziam parte dos objetivos da aula. A finalidade era que os alunos considerassem seu autoconhecimento sobre o movimento corporal como base para, posteriormente, entender a explicação. A dança viria apenas para motivá-los a aprender o conteúdo.

Mais do que apenas uma manifestação artística ou um movimento estético e plástico, como passou a ser considerada no decorrer de sua história, a dança pode comportar em seu interior, também, a perspectiva de ter os seus procedimentos utilizados como recurso para novas aprendizagens do indivíduo. Não há como não cogitar a sua imersão nos vários contextos sociais e, especialmente, no contexto educacional (ZANOLO, 2009). Vincular a dança ao ensino do conteúdo proposto leva os alunos a compreenderem o que de fato a teoria propõe quando estão executando a prática.

\subsection{EM BUSCA DE UMA POSSIBILIDADE}

Tomando por base as observações, bem como a oficina de dança, elaboramos o material para ser aplicado em uma sala do primeiro ano do ensino médio de Educação de Jovens e Adultos (EJA), modalidade de escola também inclusiva, dividido em etapas, sendo:

- $\quad$ Uma dinâmica inicial com dança;

Levando em conta que as escolas não possuem um espaço adequado para a prática de dança, foi preciso repensar a maneira de sentir as ondas sonoras em uma sala de aula comum. No nosso caso, havia apenas um aluno surdo e foi necessário substituir a caixa amplificadora de som por uma mini caixa de som portátil para que ele percebesse a vibração que indicaria o ritmo musical. 


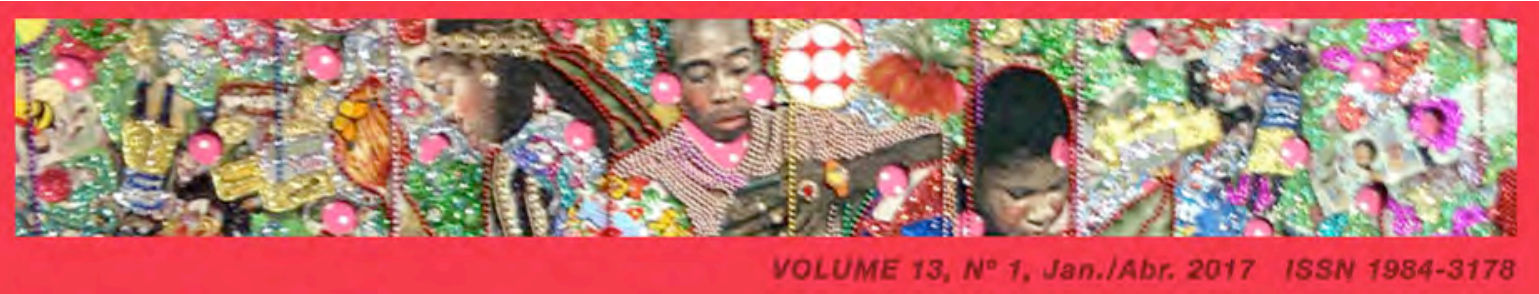

Neste estudo, utilizamos uma mini caixa de som a DY 09, um aparelho de fácil transporte, com boa amplificação do som para os alunos ouvintes, ao passo que a percepção vibratória para quem a segura é considerável. Como nos afirma Nishida (2009), na palma da mão, os campos receptivos dos corpúsculos de Pacini, mecanoreceptores cutâneos de estímulos vibratórios, são amplos.

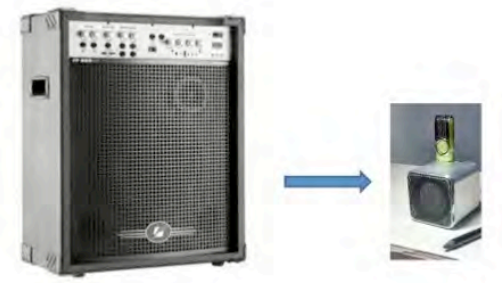

Figura 1 - Comparando o tamanho das caixas amplificadoras, tendo como ponto referencial um lápis e um pen drive. Fonte: Acervo dos autores.

Pensamos na possibilidade do aluno surdo segurar o objeto enquanto os demais escutavam a música: foi a solução adotada. Algumas pesquisas como a de Yuko et al (1999) demonstraram que surdos podem, eficientemente, detectar o ritmo com as mãos e os pés durante atividades de dança utilizando estímulos vibro táteis em contato com a pele, por meio dos corpúsculos de Pacini, que se localizam na derme profunda e respondem rapidamente a vibrações de alta frequência (250 estímulos por segundo).

Levando em conta o tempo de aula, pensamos em uma dinâmica com apenas uma música coreografada com movimentos solos para que os alunos relacionassem os movimentos de alguns ossos e articulações específicas de nosso corpo, como os braços, por exemplo, por meio de flexão e adução, movimentos rotativos dos ombros, deslocamento das pernas no sentido frente/trás e laterais, os movimentos dos ossos classificados em imóveis, semimóveis e móveis e, por fim, movimentos circulares do quadril para direita e esquerda. 


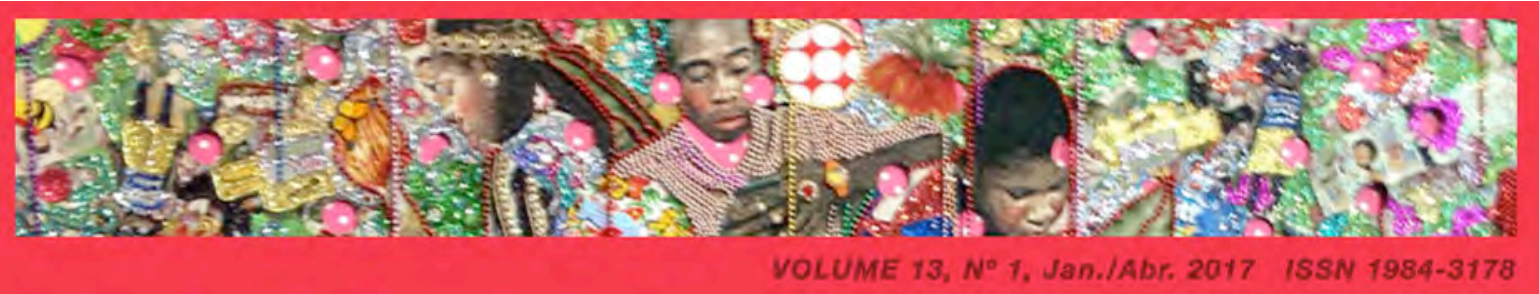

A música escolhida para desenvolver a dinâmica é intitulada Bailando ${ }^{2}$, por ter o ritmo marcado por uma batida grave bem marcada, de fácil percepção tanto pela audição quanto pela vibração. "O receptor converte a energia mecânica em uma resposta elétrica, cuja magnitude é proporcional à intensidade do estímulo aplicado" (BARRET et al, 2014, p.161) é o que se chama de codificação sensorial e permite ao surdo perceber a existência do som.

- Explicação do conteúdo: A elaboração do material visual para explicação.

Após a dinâmica da dança como elemento introdutório, procedemos com a explicação do conteúdo de forma condensada, uma vez que, nessa aula, o objetivo era sintetizar o conteúdo do sistema ósseo e relacioná-lo com o cotidiano do aluno e, para tal, elaboramos uma apresentação para ser usada no projetor multimídia.

Ter alunos surdos em sala nos fez recorrer a elementos visuais, fundamentais para elaborar boas aulas, visualmente claras, facilitando a atuação do ILS e a compreensão do aluno surdo. Uma boa apresentação de slides, por exemplo, é fundamental para alunos ouvintes e para os alunos surdos (LACERDA e SANTOS 2013, p. 191). Como referência dos tópicos trabalhados, utilizamos o livro didático adotado pela professora para nortear nossa aula de fechamento, respeitando o conteúdo ministrado pela mesma.

- $\quad$ Aplicação de um questionário.

Como proposta avaliativa, elaboramos uma atividade com questões relacionadas ao conteúdo, apresentando imagens para auxiliar a compreensão e resposta dos alunos. A

\footnotetext{
${ }^{2}$ Bailando, de autoria do Cantor e compositor Henrique Iglesias, em uma versão adaptada pelo cantor Luan Santana produzida pela Universal International Music 2014. Disponível em: https://www.youtube.com/watch?v=-DVanEJVhCA.
} 


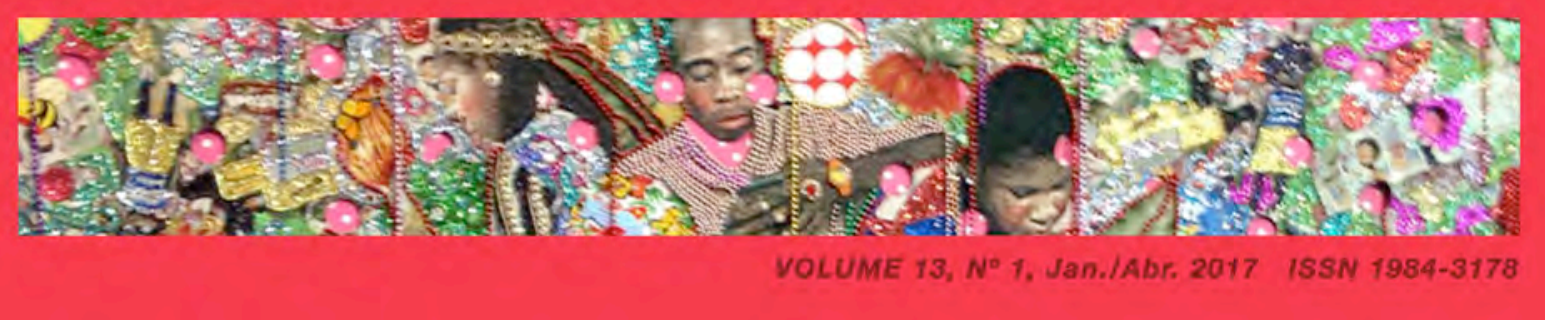

aplicação do questionário tornou-se necessária para compreender se, de fato, a aula diferenciada foi significativa para os alunos, individualmente, e se houve aprendizado, além de que permitir coletar as impressões acerca da aula proposta.

\section{RESULTADOS E DISCUSSÃO}

Um dos requisitos para titulação do Mestrado Profissional é a produção de instrumentos pedagógicos. Dessa forma, no contexto dessa pesquisa, desenvolveu-se, como produto educacional, um roteiro de aula diferenciada.

Foi escolhido para a aplicação uma turma da Educação de Jovens e Adultos visto que segundo a Declaração de Hamburgo, a mesma perpassa a aprendizagem formal. Inclui a educação formal e a não formal e o espectro da aprendizagem informal e incidental disponível numa sociedade multicultural, onde os estudos baseados na teoria e na prática devem ser reconhecidos (UNESCO, 2008). Uma educação que percebe a importância do aspecto cultural e social no processo de ensino-aprendizagem e, em especial, na EJA, pois a faixa etária não é o supremo vilão das dificuldades, mostra seu compromisso social (MARQUES, 2007).

Um fator determinante para a produção da aula foi considerar a presença do profissional intérprete de LIBRAS envolvido no processo, pois somente o material visual e a dinâmica não são suficientes para a compreensão do aluno, que precisa ser instruído na sua língua natural, a LIBRAS, visto que a realidade atual das escolas inclusivas não proporciona uma educação bilíngue, sendo essa aula diferenciada ministrada na Língua Portuguesa oralizada e interpretada para língua de sinais.

Precisamos levar em conta que a percepção sonora acontece naturalmente pelo sentido da audição e que cada caso é um caso quando discorremos sobre a surdez, visto que a percepção vibratória pode ocorrer ou não, dependendo de onde o aparelho auditivo foi lesionado. Entretanto, se ainda assim desconsiderarmos toda a percepção auditiva, a vibração ocasionada pelo estímulo do som pode ser assimilada pelo sentido que conhecemos como tato, que não ocorre somente pela pele, mas também internamente no corpo humano. 


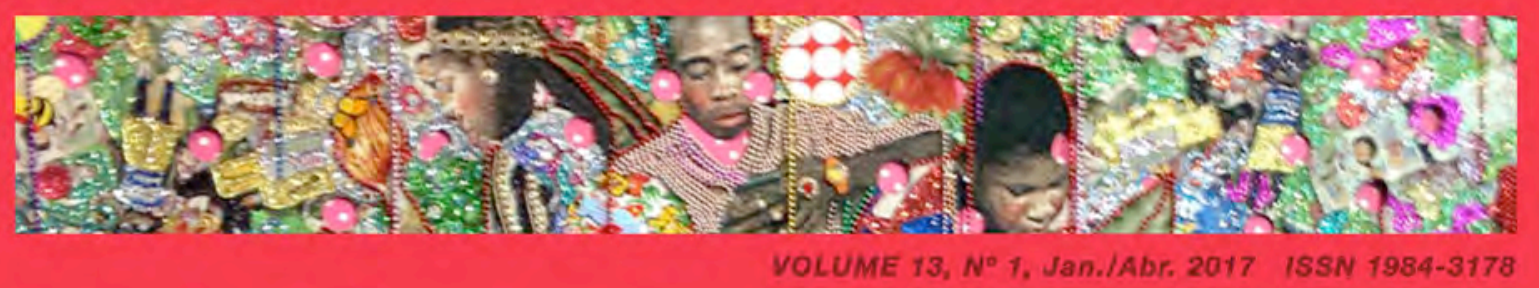

Às vezes, o que achamos ser uma vibração pouca intensa, para eles pode ser suficiente, já que o corpo humano não é dotado apenas do que conhecemos como os cinco órgãos sensoriais, tato, visão, audição, olfato e paladar. Existem outras estruturas relacionadas ao sensorial humano e, para o caso da percepção sonora, falaremos um pouco sobre o sistema sensorial somático, a condição que permite ao ser vivo experimentar sensações nas distintas partes do corpo humano.

Os receptores desse sistema, segundo Sonza (2014), encontram-se repartidos por todo corpo que servem para detectar os estímulos mecânicos, químicos e físicos. Para o caso da dança entendemos que os receptores citados na tentativa de corroborar com a hipótese seriam os: Mecanorreceptores - o Tato; Proprioceptores - localizados no músculo; Pressão localizados nos vasos; Equilíbrio - labirinto, localizado no ouvido e auditivos - cóclea. No caso dos surdos descartando a hipótese do uso dos receptores cocleares e focamos na percepção tátil como a mais aguçada.

Costumamos chamar de tato a sensação evocada pela estimulação de receptores cutâneos, os mais superficiais contidos na epiderme, denominamos de pressão e os mais profundos contidos na derme, consideramos como vibração. Assim, para um mesmo estímulo mecânico cutâneo, os grupos de receptores respondem de maneira peculiar. A qualidade da informação mecânica dependerá do tamanho do campo receptivo do receptor e da densidade. Isso significa que não possuímos a mesma sensação em toda superfície corporal.

Dentre os mecanoreceptores do tato encontram-se os Corpúsculos de Pacini, que se localizam profundamente na pele, medem menos de $4 \mathrm{~mm}$, são ovóides e percebem os estímulos de pressão, como na ilustração a seguir proposta por Nishida (2012). 


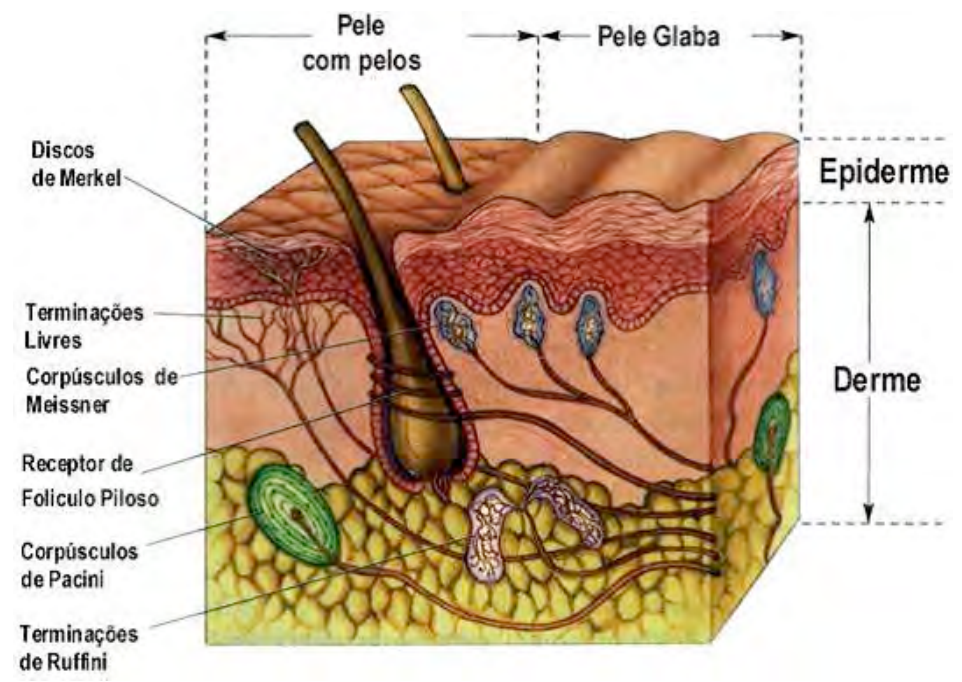

Figura 02- Tipos de receptores cutâneos. Fonte: Nishida, 2012, p.62.

Estão distribuídos, segundo Veja et al (2009), em regiões do tecido subcutâneo, no tecido conjuntivo próximo a tendões e articulações, nas membranas intraósseas do antebraço e da perna, no perimísio de músculos, no pâncreas e seu mesentério, em diversas serosas, sob membranas mucosas, nas glândulas mamárias e na genitália de ambos os sexos. Resumidamente, por todo o corpo.

Para Nishida (2012), são receptores de adaptação rápida a deformações teciduais, portanto, ótimos detectores de vibração mecânica na faixa de 30 a $800 \mathrm{~Hz}$. As ondas mais graves, geralmente produzem sons abaixo de $300 \mathrm{~Hz}$ responsáveis por uma melhor estimulação dos corpúsculos.

O corpo humano é dotado de matéria tanto sólida quanto líquida, o que o torna um meio favorável à propagação do som. A vibração que ocorre em nosso organismo provocada pela propagação das ondas sonoras deve-se, também, ao fato de que somos constituídos por moléculas que vibram. Essas moléculas, vibrando em conjunto, determinam uma frequência natural de vibração e quando a onda sonora passa não arrasta as partículas de ar, faz com que estas vibrem em torno de sua posição de equilíbrio, proporcionando a percepção da música (SONZA, 2014). Como nos coloca a autora Cervellini poeticamente.

O ser humano dificilmente permanecerá impassível perante uma banda ou uma escola de samba desfilando na avenida. O ritmo musical mexe com os ritmos internos, com o pulsar do coração, com a respiração, com o andar. 
Diante de um ritmo marcante surge o movimento espontâneo dos pés, o tamborilar dos dedos, o balanço da cabeça ou do corpo, o cantarolar. Ritmo é vida e quem está vivo não escapa dele (CERVELLINI, 2003, p. 76).

Os surdos, por se importarem com o visual, entendem a dança como algo visualmente agradável, por conta das vestimentas das coreografias sincronizadas, elementos que os motivam à prática, bem como a percepção da vibração que acontece em segundo plano. Ela é percebida de forma mais intensa e, ao nosso ver, mais facilitada, uma vez que, para tal percepção vibratória, nossa audição nos confunde um pouco, o que não acontece com o surdo. Sá (2008) afirma que a sensibilidade das pessoas surdas é um pouco mais aguçada que a dos ouvintes.

Não há melhores órgãos ou sistemas, mas apenas aqueles mais bem adaptados. Esses fenótipos são alvos do processo de seleção natural. E no caso das pessoas surdas, essa vibração é de fácil percepção quando se atenta para o ritmo musical. Tais informações são muito importantes para a área das ciências naturais, principalmente em tempos de novos paradigmas nesse campo do conhecimento, que deve ser prioritariamente interdisciplinar. Nossa proposta de aula diferenciada vem ao encontro das novas Orientações Curriculares do Estado de Mato Grosso.

Para compreendermos essa questão, seriam necessários observações e experimentos que vão além desse trabalho, de forma que não só o professor-pesquisador, mas também alunos, pudessem se autoconhecer e compreender como essa vibração age em seu organismo e identificá-la de forma a compreender o ritmo musical. Nesse experimento, tomamos como base o reconhecimento da vibração em nosso próprio corpo, para o ensino dos alunos no momento da execução da aula diferenciada. É importante salientar que quanto maior o espaço, mais intensa deve ser a música para que a vibração possa ser sentida de forma nítida.

Posteriormente a aplicação, questionamos a aluna surda (AS) com relação a sua opinião quanto à aula e se a mini caixa de som lhe possibilitou sentir a música. Ela nos sinalizou: 
braços a dona Maria rebolando, foi muito legal, eu gostei. Sim eu senti, mas aquela caixinha era muito pequena você deveria ter usado uma maior para ter uma vibração enorme, fazer pow, pow, pow, brincadeira! (Risos) (Tradução nossa).

Pensando na questão da visualidade não só do sujeito surdo, mas dos alunos em geral, é preciso levar em consideração que hoje todos estão cada vez mais envolvidos com tecnologias, sejam com celulares, redes sociais ou outras mídias. O professor tem que estar atento a tais transformações, dominar, pelo menos, alguma mídia, pois são recursos essenciais para deixar as aulas mais atrativas e fundamentais para diminuir a abstração de muitos dos conceitos biológicos e de outras ciências. Algumas opções para utilizar em sala de aula são: os simuladores ou softwares educacionais, o uso de recurso como áudio visual, apresentações em formato ppt. ou pps. (Slides) (SOUZA, 2014).

Os autores Lacerda e Santos (2013 p.192) defendem o slide como um recurso fundamental para o trabalho com surdos. Os professores devem reivindicar esse tipo de equipamento no espaço em que se desenvolve a educação de surdos. São inúmeras as possibilidades quanto ao uso de vídeos e imagens, que, por meio dos recursos do programa utilizado, movimentam-se, relacionam-se por esquemas propostos na elaboração do material, corroborando com a aprendizagem do conteúdo por todos. O uso do equipamento foi pertinente a metodologia proposta e pode ser constatado em algumas respostas retiradas do questionário.

Nesta pesquisa, a aplicação do questionário tornou-se necessária para compreensão se de fato a estratégia empregada nesta aula foi significativa para os alunos e se houve aprendizado. Em uma das questões, pediu-se aos alunos que relatassem quais as impressões que obtiveram com a aula diferenciada, e foi perceptível na fala do aluno (A1) que o uso de imagens, bem como do projetor foram fatores que contribuíram positivamente na aprendizagem dos alunos como um todo.

Ele diz: "Sim, foi ótima a aula vendo os ossos na tela ficou muito fácil a descrição do que seria móvel e imóvel e etc.” Esta fala demonstra a importância da visualidade não só para os alunos surdos, mas para os ouvintes também. Pensando nos alunos surdos, Campello nos traz como fator importante para a aprendizagem do aluno surdo, que: 
A pedagogia visual consiste na exploração de várias nuances, ricas e inexploradas, da imagem, signo, significado e semiótica visual na pratica educacional cotidiana, procurando ao oferecer subsídios para melhorar e ampliar o leque dos olhares aos sujeitos surdos e sua capacidade de captar e compreender o saber e a abstração do pensamento imagético dos surdos. (CAMPELLO, 2007, p.130).

O questionário ainda nos permitiu coletar as impressões quanto à aula proposta, visando perceber a opinião dos alunos sobre a estratégia aplicada em uma sala com uma colega surda. Para nossa surpresa todos participaram de forma voluntária, visto que tínhamos na aula alunos com idades que variavam entre 20 a 70 anos e todos responderam ao questionário de forma satisfatória.

Foi perceptível que a aula foi bem aceita por todos e confirmada por meio das repostas dos alunos, como (A02): "Ótimo, muito bom mesmo deveria ter mais aula como essa"; e (A04): "Sim achei muito legal, uma aula super diferente".

A fala do aluno (A02) vai ao encontro do que diz Krasilchik (2004), que os professores não utilizam linguagem nem instrumentos que cativem a atenção do aluno, para que a aula se torne informativa e divertida, tornando a, ao contrário, cansativa e que nada ou quase nada contribui para a formação do aluno. Os professores têm receio de AD e justificam a idade, dentre outros fatores, para não inovarem, pensando que não serão aceitas pela turma, contudo a resposta da aluna contraria esta visão.

Com relação à dinâmica interativa com dança na sala com a aluna surda, os colegas foram indagados se os mesmos pararam para pensar em algum momento que na sala havia a colega que não ouvia, oito alunos alegaram pensar na aluna, conforme algumas referências que se seguem:

A05: "Sim, achei muito divertido e gostaria que isso acontecesse mais vezes. A nossa colega surda está há tanto tempo com a gente, que a gente acaba até esquecendo que ela e surda".

A08: "Sim, pois já acostumei em vê-la todos os dias com a gente e pensei: como sentia a energia da música?" 
A03: "Na minha sala tem uma aluna com esta deficiência, surda, mas ela é muito inteligente, parece não ter dificuldade de aprender como eu tenho, por isso eu acho ela muito interessante".

A01: "Sim, notamos a presença de nossa colega surda (entre aspas) na sala e de como ela interagiu sem nenhuma dificuldade".

Analisando as falas dos alunos, compreendemos que a convivência torna a surdez algo que não tem relevância. Os alunos começam a perceber as capacidades do colega e não se sobressai o que acreditam ser limitações, a surdez passa a ser apenas mais uma característica, dentre as muitas que constituem o sujeito surdo.

No final, percebemos que houve muito interesse por parte dos alunos na metodologia diferenciada. Ao terminar a dinâmica com a música, os alunos pediram para que a repetíssemos. Não sentimos rejeição às estratégias metodológicas, por parte de aluno algum da sala, e tampouco da professora regente, que observou toda a aula.

Como pesquisadores também nos surpreendeu a pró-atividade dos alunos pesquisados em participar da aula diferenciada. Todos se propuseram, espontaneamente, a participar, o que nos causou espanto considerando que havia muitos senhores e senhoras idosos, que, geralmente, nos levaram a pensar que ficariam acanhados em participar visto que precisariam se expor na frente dos colegas.

No intuito de não excluir o aluno surdo, entendemos que é possível trabalhar não só a dança, mas também a música como recurso pedagógico. Os alunos da sala na qual o experimento foi aplicado interagiram a todo o momento e participaram ativamente do processo de ensino-aprendizagem e as respostas dos alunos corroboram para esta afirmação.

Sabemos que a formação inicial dos professores no quesito educação inclusiva ainda está aquém da necessidade. Hoje os cursos de licenciatura já possuem em sua matriz curricular a disciplina obrigatória de LIBRAS. Entretanto, muitos ainda alegam que o professor não é obrigado a saber LIBRAS.

Entendemos que ele realmente não precisa ter a fluência na língua, mas compreender minimamente as especificidades do aluno surdo, bem como, aprender sinais que possibilitem uma interação entre ambos, é importante para entender, mesmo superficialmente, que esse 


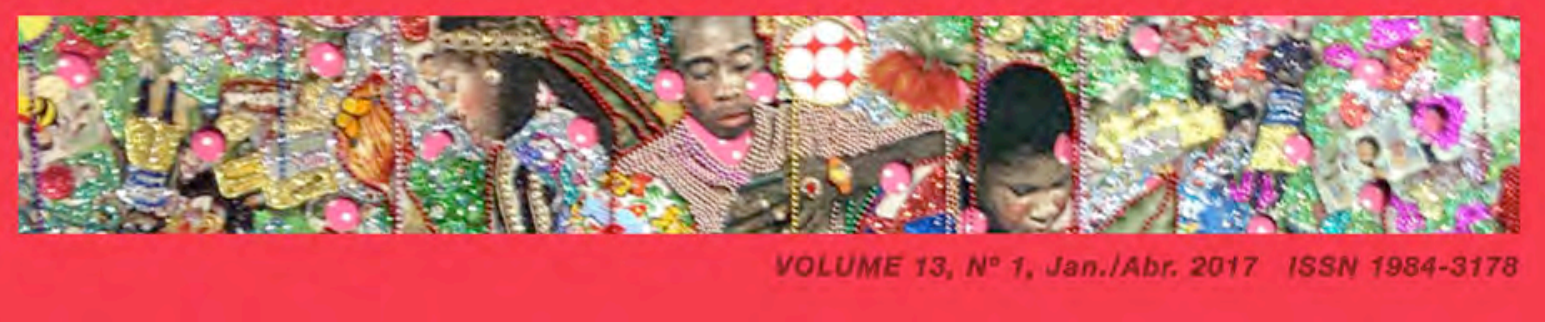

aluno aprende visualmente e que as estratégias metodológicas orais pouco contribuem para a sua aprendizagem.

A disciplina de LIBRAS ofertada na formação dos futuros licenciados possui carga horária de 60 horas, em média. Assim como vários cursos básicos da língua de sinais, que não conseguem o desenvolvimento de fluência no estudante por se tratar de uma língua tão complexa quanto as demais.

Percebemos que a professora responsável pelas aulas de Biologia encontra diversas barreiras para possibilitar um ensino de qualidade para os alunos, sendo a variável tempo de aula, nos contextos de nossas observações, um fator determinante para desanima-la a usar metodologias inovadoras, visto que a mesma trabalha o dia todo e precisa ministrar o conteúdo proposto neste horário reduzido.

A falta de tempo também foi um fator percebido, à qual atribuímos o tratamento diferenciado em relação aos alunos surdos do turno matutino dado pela mesma professora com os da EJA, que acontece no período noturno, com carga horária reduzida a professora mal consegue contextualizar e explicar os conteúdos de uma forma geral.

Como sugestão, acreditamos que o produto da pesquisa pode ser empregado em aulas que envolvam a explicação de todos os sistemas humanos, sejam eles respiratório, circular, nervoso bem como o muscular e o ósseo. Salientamos que esta prática seria melhor desenvolvida se aplicada como forma de fechamento do conteúdo, o que permitiria um alcance maior quanto à relação do conteúdo com a atividade prática da dança, além de possibilitar aos alunos a percepção de que todos estão interligados e são interdependentes.

Entendemos que é necessário respeitar aqueles alunos, surdos ou não, que por algum motivo não se sintam à vontade em praticar a dança, além do que, não significa que tal experimento seja uma receita de sucesso, afinal de contas, o ato de ensinar não tem fórmula, depende de cada contexto e cada momento interativo deve ser levado em consideração.

Existe, ainda, a possibilidade de o conteúdo ser trabalhado de forma interdisciplinar, minimamente, com os professores de Educação Física, considerando atividade prática, e de Física para uma discussão dos movimentos e ondas sonoras entre outras questões 
relacionadas; entretanto, a vivência desse recurso nas diferentes disciplinas, certamente, trará mais complexidade à atividade proposta.

\section{CONSIDERAÇÕES FINAIS}

A elaboração e execução do roteiro de aula nos fez compreender que é possível utilizar a metodologia e que o fato de ser uma aula diferente (AD), principalmente por envolver dança - um elemento pouquíssimo utilizado dentro do currículo escolar, com exceção à Educação Física esporadicamente para eventos -, despertou o interesse dos alunos pelo conteúdo estudado, caracterizando-se, assim, como um elemento motivador para a aprendizagem em salas com uma aluna surda inclusa.

\section{REFERÊNCIAS}

AUSUBEL, D.P., NOVAK, J.D; HANESIAN, H. Educational psychology. New York: Holt, Rinehartand Winston. Rio de Janeiro: Editora Interamericana. 1980.

BARRET, K.E. et al.Fisiologia médica de Ganong. 24a ed. Porto Alegre, RS: AMGH Editora Ltda/ Mc Graw Hill Education Holdings. 2014.

CAMPELLO, A. R. S. Pedagogia visual/sinal na educação dos surdos. In: QUADROS, R. M.; PERLIN, G. (Orgs.). Estudos surdos II. Petrópolis: Arara azul, 2007.

CAMPOS, M. C. C; NIGRO, R. G. Teoria e prática em ciências na escola: o ensino-aprendizagem como investigação. São Paulo: FTD, 2009.

CERVELlini, N. H.A Musicalidade do surdo: representação e estigma. São Paulo: Plexus Editora, 2003.

HARDOIM, E. L. et. al. A educação inclusiva e os princípios da Carta da Terra: um profícuo diálogo na busca da justiça social. In: Escola, comunidade e educação ambiental: reinventando sonhos, construindo esperanças. Cuiabá: Grafica Print, 2013.

KRASILCHIK, M. Prática de ensino de biologia, 4ª Edição, Editora USP,São Paulo, 2004.

LACERDA, C. B. F; SANTOS, L. F Tenho um aluno surdo, e agora? Introdução a libras e educação de surdos. São Carlos, Ed UFSCAR, 2013. 
LEMOS NETO, L. et al. O ensino de química e a aprendizagem de alunos surdos: uma interação mediada pela visão. In: ENCONTRO NACIONAL DE PESQUISA EM EDUCAÇÃO EM CIÊNCIAS, 6, 2007. Anais...Belo Horizonte: Associação Brasileira de Pesquisa em Educação em Ciências, 2007. v. 1.p. 1-12.

LOPES, M. C; Surdez \& Educação $2^{\circ}$ ed. rev. ampl. Belo Horizonte: Ed. Autêntica, 2011.

MACHADO, P. C. A mediação da aprendizagem do surdo através da informática: CD-ROM de Biologia. São José, SC: [s.n.], 2003.

MARQUES, R. R. Educação de Jovens e Adultos: um diálogo sobre a educação e o aluno surdo. In: QUADROS, R. M.; PERLIN, G. (Orgs.). Estudos surdos II. Petrópolis: Arara azul, 2007.

MOREIRA, M. A. Aprendizagem significativa. Brasília: Ed. UNB, 1999.

NISHIDA, S. M. Apostila do curso de Fisioterapia. São Paulo: Unesp. 2012.

PEREIRA, L. L. S; BENITE, C. R. M; BENITE, A. M. C. Aula de química e surdez: sobre Interações Pedagógicas Mediadas pela Visão. Química Nova Escola.v.33, n1, 47-56,2011.

QUADROS, R. M. In: Mendes, E. G.; Almeida, M. A.; Williams, L. C. de A. (Org.). Temas em educação especial IV. São Carlos: EdUFSCar, p. 55-61, 2004.

SÁ, N. R. L. Os surdos, a música e a educação, revista Dialógica v02, n 05, UFA 2008.

SASSAKI, R. K. Inclusão: Construindo uma sociedade para todos. Rio de Janeiro: WVA, 1997.

SKLIAR, C. A. A surdez: um olhar sobre as diferenças. Porto Alegre: $6^{\circ}$ ed. Mediação, 2013.

SONZA, A. Efeitos da vibração de corpo inteiro na sensibilidade cutânea, equilíbrio, variáveis fisiológicas e cargas de aceleração associadas. Porto Alegre, RS, 2014. Tese (Doutorado em Neurociência) - Universidade Federal do Rio Grande do Sul, UFRGS, 2014.

SOUZA, R. W. L. Modalidades e recursos didáticos para o ensino de biologia. Revista eletrônica de biologia-REB Volume 7 (2): 124-142, 2014.

STROBEL, Karin. As imagens do outro sobre a cultura surda. Florianópolis $3^{\text {a }}$ Edição Ed. UFSC, 2013.

UNESCO. Alfabetização de jovens e adultos no Brasil: lições da prática — Brasília, 2008.

VEJA, J.A. et al. The Meissner and Pacinian sensory corpuscles revisied new data from the last decade. Microscopyresearchandtechnique, v.72, n.4, p. 299-309, abr.2009.

VIGOTSKI, L. S. A formação social da mente. São Paulo: Martins Fontes (1999).

Pensamento e Linguagem. 4 ed. São Paulo: Martins Fontes, 2008.

YUKO, O., Reiki, Y., \& KAZUO, K. Dance timing for deaf person through vibrotactile stimuli: Technical report. Institute of Electronics, Informationand Communication Engineers, 99, 35-42, 1999. 
ZANIOLO, L. O. Dança como prática social: um recurso metodológico para processos educativos e inclusão escolar. In Dall’Acqua, M. J. C; Zaniolo, L. O. Educação inclusiva em perspectiva: reflexões para a formação de professores. 1 ed. Curitiba: Editora CRV 2009.

Recebido em 25 de setembro de 2016 Aprovado em 30 de março de 2017 